\title{
ОБРАЗОВАТЕЛЬНАЯ СРЕДА ВУЗА КАК ФАКТОР ПОВЫШЕНИЯ КАЧЕСТВА ОБУЧЕНИЯ РКИ ${ }^{1}$
}

\section{THE ROLE OF INTERACTIVE METHODS IN TEACHING RUSSIAN AS A FOREIGN LANGUAGE}

\section{F. Autleva \\ L. Bzegezheva}

Summary: The article substantiates the relevance of the topic of improving the quality of teaching Russian as a foreign language, taking into account the global trends in the development of education, as well as the requirements set out in the state documents of the Russian Federation for the quality and level of export of educational services provided by Russian universities. On the basis of this, the author puts forward and justifies the assumption about the importance of the educational environment of the university as a set of social, subjectspatial, personal-developing, etc. an eco-component for designing students ' own educational trajectories and stimulating the professional and personal development of teachers. The author substantiates the terminological content of the concept of "educational environment of the university" within the framework of the problem under consideration, describes one of its significant components-the information education of teachers; one of the innovative forms of its implementation in a modern university is proposed. The article substantiates its potential in improving the quality of teaching RKI on a linguistic and cultural basis, taking into account the socio-cultural and didactic features of the organization of the educational process in the countries from which foreign students come. The dependence of the quality of assimilation of educational material by students on the socio-cultural, technological, educational, etc. characteristics of the educational environment is also emphasized. The problem of the involvement of the entire teaching staff in solving the issues of improving the quality of RCT teaching is outlined, which implies the development of not only the linguistic, but also the methodological component of their professionalism.

Keywords: teaching Russian as a foreign language, educational environment, quality of education, the role of a teacher, informal education, interactive mini-forms, virtual coworking centers, differentiated tasks, digitalization, mentality of students.

\author{
Аутлева Фатима Аминовна \\ К.филол.н., доцент, Майкопский государственный \\ технологический университет \\ autlevaf@yandex.ru \\ Бзегежева Лариса Казбековна \\ К.филол.н., доцент, Майкопский государственный \\ технологический университет \\ bzegezheva@yandex.ru
}

Аннотация: В статье обоснована актуальность темы повышения качества обучения русского языка как иностранного с учётом мировых тенденций развития образования, а также изложенных в государственных документах Российской Федерации требований к качеству и уровню экспорта образовательных услуг, осуществляемых российскими вузами. На основе этого автором выдвинуто и обосновано предположение о значении образовательной среды вуза как совокупности социальной, предметно-пространственной, личностно-развивающей и т.п. компонент для конструирования обучаемым собственных траекторий образования и стимулирования профессиональноличностного развития педагогов. Авторами обосновано терминологическое наполнение понятия «образовательная среда вуза» в рамках рассматриваемой проблемы, описан один из значимых её компонентов - информальное образование педагогов; предложена одна из инновационных форм его реализации в современном вузе. Обоснован её потенциал в повышении качества преподавания РКИ на лингвокультурологической основе с учётом социокультурных и дидактических особенностей организации образовательного процесса в странах, откуда прибывают иностранные студенты. Также подчёркивается зависимость качества усвоения учебного материала обучающимся от социокультурной, технологической, образовательной и т.п. характеристик образовательный среды. Обозначена проблема включённости всего педагогического коллектива в решение вопросов повышения качества обучения РКИ, что предполагает развитие не только лингвистической, но и методической составляющей их профессионализма.

Ключевые слова: обучение русскому как иностранному, образовательная среда, качество образования, роль преподавателя, информальное образование, интерактивные мини-формы, виртуальные коворкинг-центры, дифференцированные задания, цифровизация, ментальность обучаемых. овременное обучение русскому языку как иностранному (далее - РКИ) в российском вузе неотделимо от общемировых тенденций модерниза- ции образования, так как, по справедливому замечанию исследователя А.В. Обскова, «меняются тенденции в образовании, которое становится открытым, инноваци-

Грант Министерства просвещения Российской федерации на реализацию мероприятий, направленных на полноценное функционирование и развитие русского языка, ведомственной целевой программы «Научно-методическое, методическое и кадровое обеспечение обучения русскому языку и языкам народов Российской Федерации» подпрограммы «Совершенствование управления системой образования» государственной программы Российской Федерации «Развитие образования» 
онным, интерактивным, происходит огромный рывок в развитии технических средств» [8, с. 120]. Активизация интереса к изучению русского языка, возможность получить профессиональное образование. В России закономерно выдвигают на первый план проблему повышения качества преподавания (и соответственно усвоения студентами, слушателями) РКИ, и интерес к этой актуальной и перспективной области научного дискурса не ослабевает [см., например,2,4,6]. Тем более что повышение качества преподавания РКИ соотносится с экономическими и имиджевыми вопросами развития экспорта образовательных услуг российских вузов, повышения их конкурентоспособности. Это соответственно обозначает новые требования к подготовке будущих специалистов, а также к профессионализму людей, обеспечивающих данную подготовку.

Русский язык, выступая инструментом учебного познания и учебной коммуникации, представляет значительную трудность для иностранных студентов. По наблюдениям отдельных исследователей, невысокий уровень владения русским языком на начало целенаправленного интенсивного обучения показывают, как правило, около 70 \% респондентов, что признаётся недостаточной подготовкой к усвоению терминологического аппарата учебных дисциплин, понимания лекционного материала и т.п. [см., например,1,10].

Большое значение для решения обозначенных выше проблем имеет, на взгляд автора, создание образовательной среды вуза, выступающей фактором повышения качества обучения РКИ.

Образовательная среда в работах учёных предстаёт как как особое педагогическое явление, соотнесённое с условиями образования, обеспечением его продуктивности $[9,12]$. А собственно понятие «среда» в научном дискурсе коррелируется с триединым концептом «пространство/ окружение/ условия». Не ставя перед собой цель детально рассматривать данную взаимосвязь, отметим, что многими учёными подчёркивается зависимость качества усвоения учебного материала обучающимся от социокультурной, технологической, образовательной и т.п. характеристик среды $[7,13]$.

В то же время хотели бы особо подчеркнуть, что во многих исследованиях представлено понимание образовательной среды в тесной корреляции с вопросами самообучения и саморазвития. Так, например, как отмечает Л.С. Выготский, образовательную среду можно рассматривать только в тесной взаимосвязи компонент (социальной, предметно-пространственной, личностно-развивающей, информационной и т.п.), и образовательная среда, на взгляд учёного, является средством и фактором конструирования обучаемым и обучающим «собственной среды развития» в контексте раскрытия личностной индивидуальности [3].

В.Н. Новиков определяет образовательную среду как профессионально и личностно стимулирующую, которая в совокупности материально-технологических, управленческих, методологических и психологических факторов вузовской реальности «побуждает субъектов образовательного процесса $к$ профессионально-личностному развитию и саморазвитию» [7, с.2] .

На наш взгляд, это соотносится, в том числе, с проблемой включённости всего педагогического коллектива в решение вопросов повышения качества обучения РКИ и предполагает развитие не только лингвистической, но и методической составляющей их профессионализма, в том числе:

- учёт социокультурных особенностей студентов, изучающих РКИ, а также учёта специфики организации языкового образования в учебных заведениях их стран;

- развитие навыков выбора адекватных методических приемов и дидактических средств обучения, которые способствуют преодолению трудностей понимания иностранным студентом учебного материала;

- переход в преподавании на интерактивные миниформы и дифференцированные задания, а также обеспечение нового качества реализации принципа наглядности и доступности в применении цифровых средств обучения;

- серьёзная работа преподавателя над собственным артикуляционным аппаратом, соблюдением языковых и речевых норм для правильного понимания и адекватного произнесения их иностранными студентами (с ведением словариков опорных слов, терминов и т.п.);

- выбор и утверждение такого стиля педагогического общения, который обусловливает тактичное и толерантное отношение к различным конфессиональным и национальным особенностям обучающихся, всемерный учёт данной специфики при отборе материала и организации обучения.

Именно данный подход, на взгляд автора, обеспечивает способностью педагогической системы вуза гибко и своевременно «откликаться» на запросы обучающихся и обеспечивать качество образования. И в этой связи существуют определённые педагогические установки, направленные на оптимальное использование возможностей среды вуза в образовательном процессе.

К таким установкам, на взгляд автора статьи, следует отнести всемерное стимулирование преподавателей РКИ к информальному образованию и создание условий для его реализации в рамках образовательной среды вуза. 
Не углубляясь в толкование понятия «информальное образовани», которое полно представлено в Меморандуме непрерывного образования ЕС [5] и в законе об образовании Российской Федерации [11], отметим, что информальное образование в статье рассматривается как индивидуальная познавательно-развивающая деятельность педагогов, призванная обеспечивать накопление позитивного профессионального опыта за счёт собственной активности в образовательной среде вуза. Более того, большое значение здесь имеет расширение границ данной среды.

В частности, автором статьи предлагается создание совместного виртуального коворкинг-центра² между кафедрой, обеспечивающей преподавание РКИ, российского вуза и одним из вузов страны прибытия иностранных студентов. Это активизируется межкультурное и научно-педагогическое взаимодействия, которое обеспечивается проведением совместных проблемных онлайн-семинаров, методических консультаций конференций и т.п. Это обусловливает понимание преподавателем особенностей ментальности данной категории обучаемых, поиск «точек соприкосновения» культурных констант двух стран для облегчения изучения РКИ на лингвокультурологической основе, разработку заданий, совместных проектов, методических рекомендаций для студентов с учётом особенностей диалога культур двух стран.

Считаем, что подобные формы самообразования не только востребованы и возможны в условиях «цифровизации» современного образования, отсутствия языковых (при наличии хороших переводческих программ) и географических барьеров, но и обеспечивает качество обучения РКИ. Это обусловлено, в том числе, более активной позицией и заинтересованностью в обучении со стороны самих студентов, что основывается, в том числе, на уважении к преподавателю и признательности ему, вузу за внимательное отношение к культурным и образовательным традициям их страны, учёт их в организации обучения РКИ.

Таким образом, в целом, в рамках рассматриваемой проблемы можно сделать следующие выводы:

1. Внимание к вопросам повышения качества пре- подавания РКИ обусловлено общемировыми тенденциями модернизации образования; повышением в различных странах интереса к изучению русского языка, что предоставляет возможность их гражданам получить востребованное профессиональное образование в России; государственным требованием развития экономических и имиджевых аспектов экспорта образовательных услуг российских вузов.

2. Одним из направлений решения проблемы повышения качества преподавания РКИ представляется создание соответствующей образовательной среды в вузе, которая, по мнению ряда учёных (В.Н. Новиков, Л.С. Выготский, А.В. Хуторской и др.), определяется как как профессионально и личностно стимулирующая, которая в совокупности материально-технологических, управленческих, методологических и др. факторов вузовской действительности стимулирует субъектов образовательного процесса к профессионально-личностному развитию и самообразованию. В полной мере это относится и к педагогу как субъекту образовательного процесса в направлении обеспечения качества обучения РКИ.

3. Автор видит наибольшие возможности для этого в обеспечении образовательной средой вуза информального образования преподавателей РКИ и, в частности, создание совместных виртуальных коворкинг-центров между кафедрами, обеспечивающими преподавание РКИ, российских вузов и вузами стран, откуда прибывают иностранные студенты. Это будет способствовать пониманию преподавателями РКИ особенностей ментальности обучаемых, поиску «точек соприкосновения» культурных констант двух стран для облегчения изучения РКИ на лингвокультурологической основе, разработку заданий, совместных проектов, методических рекомендаций для студентов с учётом особенностей диалога культур двух стран.

Создание таких виртуальных коворкинг-центров не составит технических проблем и, более того, обладает определёнными преимуществами научно-педагогического взаимодействия в период пандемии.

\section{ЛИТЕРАТУРА}

1. Бойко, М.Г., Капинус Е.В. Способы решения проблемы отсутствия языковой среды при формирования коммуникативной компетенции в обучении иностранному языку// Актуальные проблемы гуманитарных и социально-экономических наук. 2017. № 11.С.57-61

2. Васильева Т.В., Ускова 0.А. Развитие системы преподавания РКИ - основа конкурентоспособности российского образования//Русский язык за рубежом.

2 Коворкинг (со-working или coworking, в пер. с англ. «совместно работающие») - форма взаимодействия между представителями одной или различных профессий. 
2017. № 5 (264). С. 100-104.

3. Выготский, Л.С. Педагогическая психология. М.: АСТ, Астрель, Люкс, 2005. 671 с.

4. Закаева Б.К., Олисаева 0.В., Цакоева А.А. Русский язык как иностранный в системе российского высшего образования//Труды СКГмИ (ГтУ). 2018. № 25. C. 127-132.

5. Меморандум непрерывного образования EC. 2000г. UPL: http://www.un.org/ru/documents/decl_conv/decl_education.shtml (дата 06ращения 26.09.21)

6. Мирзалиева Д.Б. Новые методы обучения русскому языку как иностранному// European Science. 2019. № 6 (48). С. $62-64$.

7. Новиков В.Н. Образовательная среда вуза как профессионально и личностно стимулирующий фактор// Электронный журнал «Психологическая наука и образование». 2012. №1. UPL: http://psyedu.ru/files/articles/psyedu_ru_2012_1_2776.pdf (дата обращения 26.09.21)

8. Обсков А.В. К проблеме организации интерактивного обучения в вузе //Вестник Томского педагогического университета. 2012. № 11. С. 120-124.

9. Слободчиков В.И. 0 понятии образовательной среды в концепции развивающего образования. М.: Экопсицентр РОСС, 2000.230 с.

10. Смирнова А.Н. Трудности подготовки иностранных курсантов к обучению в российском военном вузе и пути их преодоления//Ярославский педагогический вестник.2014 № 4 Том II.С.84-88

11. Федеральный закон «0б образовании в Российской Федерации» № 273-Ф3 от 29.12.2012 с изменениями и дополнениями, Вступившими в силу в 1 мая 2017 года. UPL: https://dokumenty24.ru/zakony-rf/zakon-ob-obrazovanii-v-rf.html (дата обращения 26.09.21)

12. Хуторской А.В. Модель образовательной среды в дистанционном эвристическом обучениW// Эйдос: интернет-журнал,2005.UPL: http://eidos.ru/ journal/2005/0901/htm ( дата обращения 26.09.21)

13. Hoff T.J., H. Pohl, J. Bartfield Creating a Learning Enviroment to Produce Competent Residents: The Roles of Culture and Context // Acad. Med.-2004.V.79.P.532-539

○ Аутлева Фатима Аминовна (autlevaf@yandex.ru), Бзегежева Лариса Казбековна (bzegezheva@yandex.ru).

Журнал «Современная наука: актуальные проблемы теории и практики»

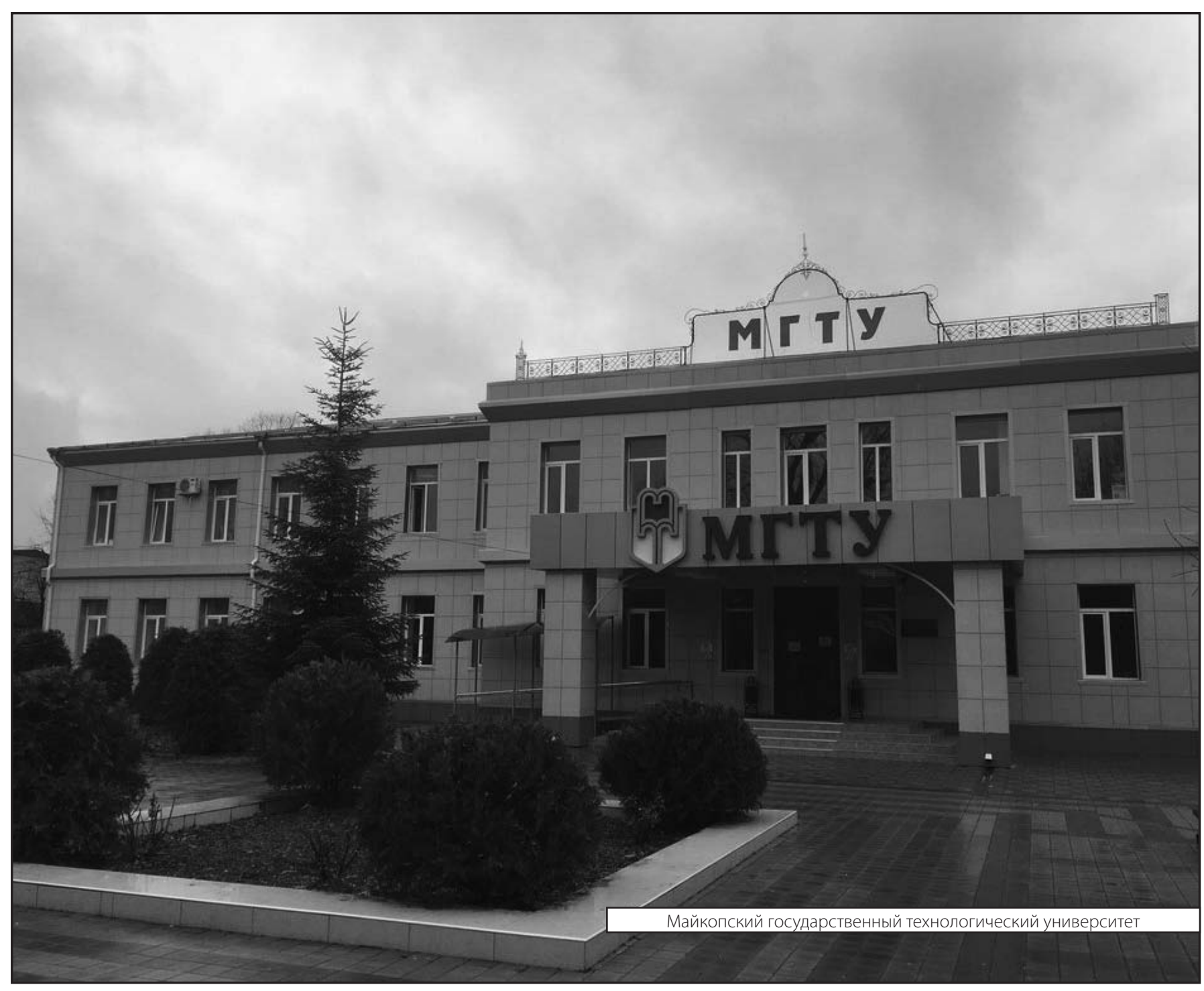

